Natural Hazards and Earth System Sciences (2001) 1: 255-262

(C) European Geophysical Society 2001

\title{
A new version of the European tsunami catalogue: updating and revision
}

\author{
S. Tinti ${ }^{1}$, A. Maramai ${ }^{2}$, and L. Graziani ${ }^{2}$ \\ ${ }^{1}$ Università di Bologna, Dipto. di Fisica, Settore Geofisica, Viale Berti Pichat 8, Bologna, Italy \\ ${ }^{2}$ Istituto Nazionale di Geofisica e Vulcanologia, Via di Vigna Murata 605, 00143 Rome, Italy
}

Received: 16 July 2001 - Accepted: 21 August 2001

\begin{abstract}
A new version of the European catalogue of tsunamis is presented here. It differs from the latest release of the catalogue that was produced in 1998 and is known as GITEC tsunami catalogue in some important aspects. In the first place, it is a database built on the Visual FoxPro 6.0 DBMS that can be used and maintained under the PC operating systems currently available. Conversely, the GITEC catalogue was compatible only with Windows 95 and older PC platforms. In the second place, it is enriched by new facilities and a new type of data, such as a database of pictures that can be accessed easily from the main screen of the catalogue. Thirdly, it has been updated by including the newly published references. Minute and painstaking search for new data has been undertaken to re-evaluate cases that were not included in the GITEC catalogue, though they were mentioned in previous catalogues; the exclusion was motivated by a lack of data. This last work has focused so far on Italian cases of the last two centuries. The result is that at least two events have been found which deserve inclusion in the new catalogue: one occurred in 1809 in the Gulf of La Spezia, and the other occurred in 1940 in the Gulf of Palermo. Two further events are presently under investigation.
\end{abstract}

\section{Introduction}

Tsunami catalogues are fundamental means to compute the tsunami potential of a given region and to determine the degree of tsunami hazard and risk to which a given segment of coast is exposed. There are questions of great relevance to civil society in order to adopt proper preparedness and emergency countermeasures and to plan sustainable development. In addition, the use of catalogues can also provide an important contribution of a scientific nature, such as, for example the identification of the tsunami sources and the related tsunamigenic mechanism, and the determination of the tsunami offshore- and nearshore-propagation.

Correspondence to: A. Maramai (Maramai@ingv.it)
For many years tsunamis were not considered worthy of independent compilations, and were included in catalogues of earthquakes (see Mallet, 1852-1854 and Baratta, 1901), volcanic eruptions (Mercalli, 1883; Baratta, 1897), or of natural catastrophes, with a description of secondary phenomena. Only around the middle of the 20th century did the need for specific tsunami compilations arise, and Heck was the first to produce in 1947 a catalogue where he included all the tsunamigenic regions in the world, by gathering material from previous earthquake catalogues. Subsequently, the structure of tsunami compilations became more adequate to the quantification needs of tsunami research by incorporating specific parameters, such as the tsunami run-up observed in the relevant coastal sites as well as the tsunami intensity (Ambraseys, 1962). A similar style was also adopted in some later works that were basically "parametric" tsunami catalogues, such as Papadopoulos and Chalkis's (1984) compilation and the paper by Papazachos et al. (1986), both on Greek events, and the Portuguese list assembled by Moreira (1968). A more complete form of catalogue was published by Antonopoulos (1980). In his work covering the tsunamis of the eastern Mediterranean, he devoted a distinct section to each event, comprising a list of quantitive parameters (as for the parametric catalogues) and, in addition, a detailed description and a discussion of original historical sources. The important concept of event reliability, i.e. a parameter expressing the degree of the author's confidence on the fact that the event in the catalogue is a real tsunami, was systematically used by Soloviev in his catalogues of the Mediterranean tsunamis, i.e. in the parametric catalogue published in 1990 as well as in the full catalogue that was published after his death by his co-workers (Soloviev et al., 1997).

Among the regional catalogues of tsunamis the Italian catalogues are worth mentioning: the first example was due to the efforts of Caputo and Faita (1984), who had the important merit to recall to the Italian community that Italian coasts were threatened by tsunamis and needed protection. This catalogue, together with its updated version (Bedosti and Caputo, 1986), differs from all the preceding and subsequent 


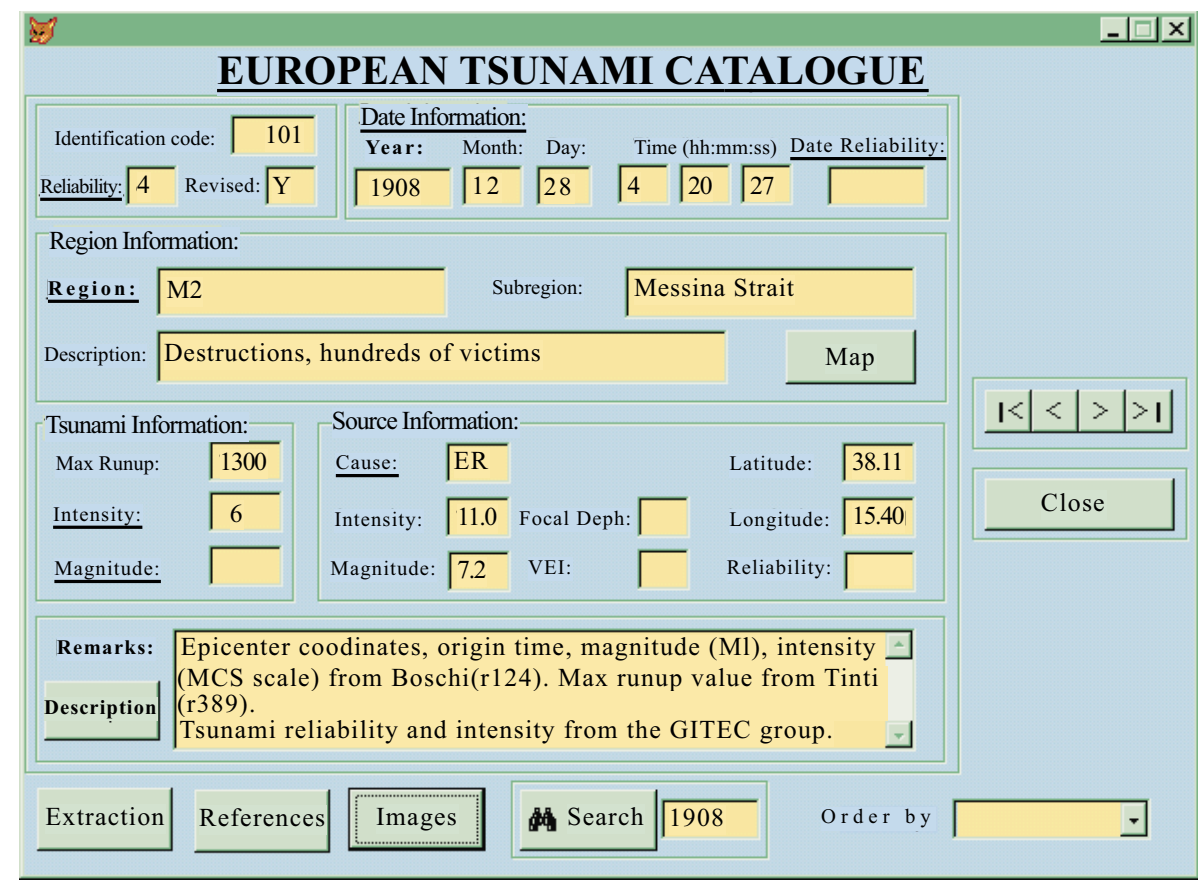

Fig. 1. Main screen of the European tsunami catalogue. The screen points to the case of the 28 December 1908 Messina Strait tsunami. The event data are contained within the large box that is in turn partitioned in 6 sub-boxes. The lateral right and bottom strips contain the functional button that can be used to interrogate the database. examples of tsunami compilations because the authors intentionally decided to include all the available historical sources and documents in it with full reproduction of the relevant excerpts, avoiding any critical interpretation and evaluation of the quality of the sources and of their content.

\section{The European tsunami catalogue}

The creation of a catalogue of tsunamis covering all of Europe was first tackled in the frame of an international project financed by the European Union called GITEC (acronym for Genesis and Impact of Tsunamis on the European Coasts): a special GITEC working group dealt with the task of specifying the basic guidelines for implementing a tsunami database with respect to unified criteria regarding the relevant tsunami parameters, the standards for the quality of the data and of the data sources, the reliability of the events, etc., and devised the general structure of the database (see Tinti et al., 1999). The first application of the GITEC catalogue structure was implemented by Tinti and Maramai who published the catalogue of the Italian tsunamis (1996) by deeply and critically revising the catalogues due to Caputo studies mentioned in the previous section. The European tsunamis catalogue was conceived as a high-priority task in the GITEC project and implemented as a digital database in the frame of the GITEC-TWO project under the name of GITEC tsunami catalogue whose versions 1.0 and 1.1 were released in April and in October 1998, respectively (see the contribution by Tinti et al., 1999 in the GITEC-TWO Final Scientific Report). It was implemented by using the Data Base Management System (DBMS) Microsoft FoxPro 2.5 running on PC platforms Windows 3.1, and later versions, and the first re- leases of Windows 95. It was planned to be a product readyto-use with a friendly interface including an on-line help facility. The catalogue includes the events with sources close to the coasts of the European countries, therefore including sources in the Norwegian and the North Sea, the Atlantic Ocean, the Mediterranean and the Black Sea, and spans a time period ranging from the pre-historical times until the present: the first entry in chronological order in the catalogue is the paleotsunami associated with the second Storegga slide in the Norwegian Sea that is estimated to have taken place some 6000 yrs BP.

In this paper we present a new version of the GITEC tsunami catalogue. The goals of our work were essentially twofold, one based on technical grounds and one based on scientific nature: (1) to realize a product that can be used on the PC operating systems released in the last few years; (2) to release a database including the result of the latest research concerning updating, revision and reappraisal of European tsunami events.

Regarding the first point we noticed that the GITEC version 1.1 could not be used correctly on a PC running under Windows 98, Windows 2000 and its latest versions, though generally it could be installed successfully on these machines. This problem was recognised to be essentially due to the fact that the DBMS FoxPro 2.5 products are not fully compatible with the new systems, and it forced us to create a completely new version of database by using the Visual FoxPro 6.0, which is a DBMS with internal architecture and programming tools that are very different from FoxPro 2.5. The consequence is that the new electronic release that we built and that we call the European tsunami catalogue is a package of modules totally diverse from the GITEC version 

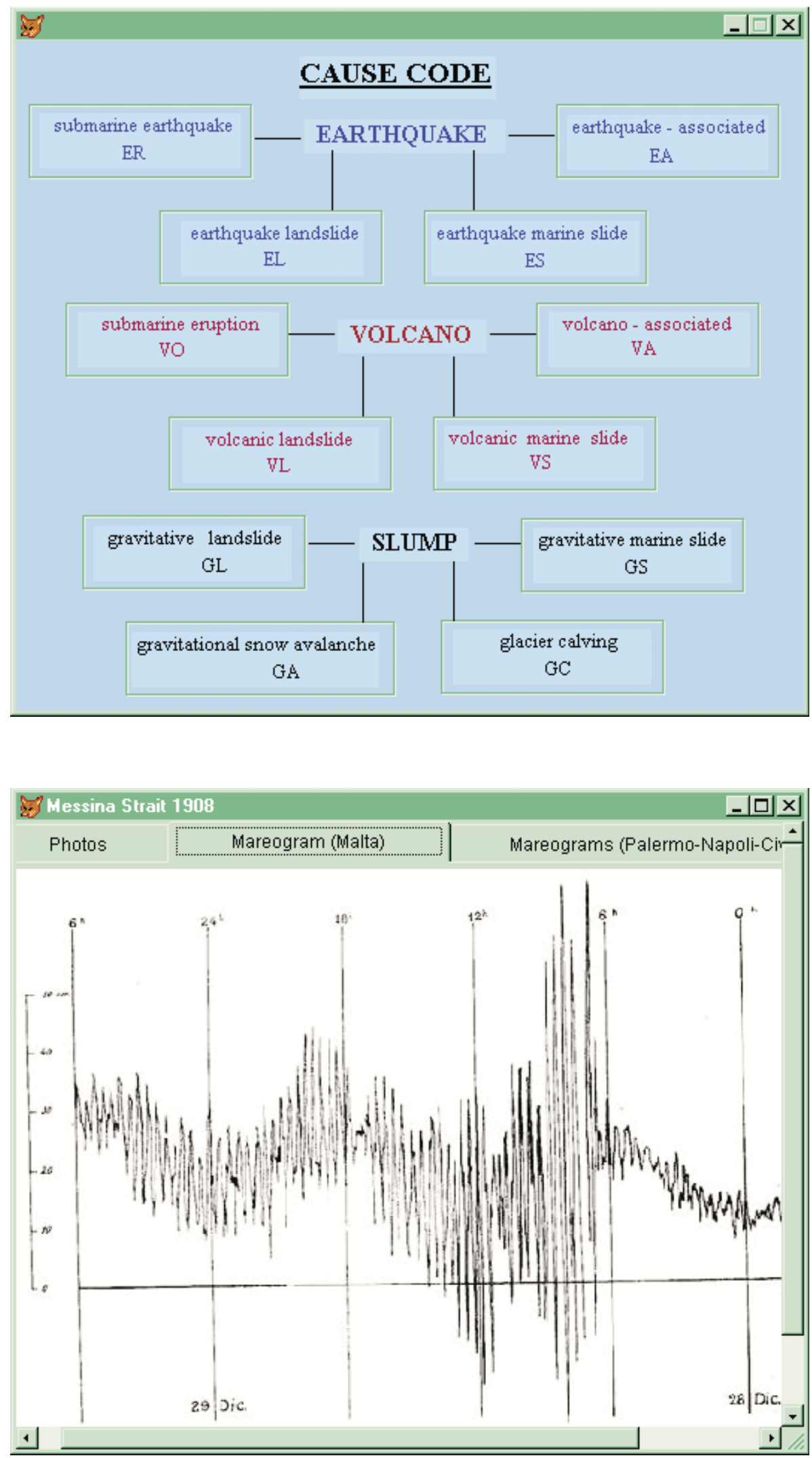

Fig. 2. Diagrammatic sketch illustrating the codes used in the catalogue to characterise the tsunami cause. This window is part of the online help; the user opens it after clicking on the cause item of the main screen and closes it simply by clicking on it.

Fig. 3. Mareogram recorded by the tide-gauge of La Valletta, Malta, during the Messina Strait 1908 tsunami. This picture is obtained by means of the button "Images" of the main screen by selecting the 1908 event first, and then by selecting the item "Mareogram (Malta)" from the 3-item menu on the top of the screen.

1.1. However, a lot of efforts have been put forth to maintain functional compatibility, or in other words, to set up a product where all the changes that we had to make remain mostly transparent to the user. Indeed, the general structure 
and interrogation tools of the previous version have been preserved. Once launched, the catalogue shows the user the main interface screen that has a double function: 1) it allows the user to interrogate all the data tables in the database system by means of functional buttons, and 2) it points to a specific tsunami event. An example of the main screen is given in Fig. 1. In this case the main screen points to the destructive tsunami that occurred in the Messina Strait, Italy, on 28 December 1908. The screen is graphically organised in sections: i) one main box covering most of the screen and comprising of 6 sub-boxes that provide data on the selected event, and ii) the strips to the right and below the main box including functional buttons to move throughout the database. Though a detailed description of how to use the database is out of the scope of this paper, it is worthwhile to provide here a synthetic hint on the available data and facilities. Basically the textual content of the main box is what one expects to find in a "parametric" catalogue. The sub-boxes contain the identification code of the event, its reliability (a numerical code from 0 to 4 expressing the probability that the event is a tsunami, where $0=$ very improbable tsunami and $4=$ definite tsunami), the event date and source region and subregion, the tsunamigenic cause, the tsunami intensity, etc. The sub-box named "remarks" is conceived to give the references for all the event parameters and data displayed in the above sub-boxes. As may be seen, references are given in the form of the first author followed by rxxx, where $\mathrm{xxx}$ is a numeric code univocally identifying the reference. The two functional buttons inside the main box can be used (by double-clicking) to obtain further information on the event. The button "Map" provides a window showing the map of the geographical region where the event occurred with the specification of the subregions. The button "Description" opens a new window on the PC screen where a synthetic illustration of the tsunamigenic cause and a full account of the tsunami can be found, with all the relevant bibliographic references. Notice that useful references are considered here with all the known written contributions on the tsunami, comprising of historical sources, specific studies (scientific papers or monographies), previous catalogues, etc. The functional buttons in the lateral strips allow the user to move to other events (see the arrow-buttons on the right), to change the sorting keyparameter (see the "order by"-button in the lower right corner: events may be orderered and searched by date, region, cause, etc.), to interrogate the references database, to perform data extractions according to single and multiple keys, etc. It is worth stressing that the references are organised as a database that is accessed through the aforementioned button on the main screen and that can be searched by using the numeric code $\mathrm{xxx}$ that is given in the event description text. It can also be searched through the author's name: in this case all the references included in the catalogue associated with the specified author are displayed. A further important tool is the "Extraction" button, allowing the user to perform a selection of events from the database according to different keys, such as date, location, cause, intensity, etc., that can also be used together to perform a multiple-key selec- tion. Furthermore, the user can rely upon an on-line help or memo facility that is activated simply by clicking on the subbox items of the main screen. For example, by clicking on the item "cause" (see Fig. 1), the user can see the diagram shown in Fig. 2, where the codes of tsunamigenic causes adopted in the catalogue are listed and explained.

All the features illustrated above were available also in the previous version of the catalogue, and the difference for the user concerns only the graphical design of the main screen. It is important, however, to point out that the present version includes new facilities: the button "Images" that is found on the bottom strip of the main screen enables one to access the database of the graphical data, containing maps, photos, mareograms, concerning the most important events. This is an addition to the old catalogue. By clicking the button, the user opens an event window with a menu allowing him to select and display the desired image. Examples are given in Figs. 3 to 5 where the catalogue images portraying, respectively, the tide-gauge records of the 1908 Messina Strait tsunami (Malta and other stations) and of the 1905 Calabria tsunami, both in southern Italy, are displayed. A further small addition is the inclusion of the functional button "Search" (see Fig. 1) allowing one to speed up the search for an event by entering the year of occurrence.

\subsection{Revision}

In the above section we have mainly explained the technical changes to the GITEC database, while here we concentrate on the modifications resulting from the scientific part of the work. The literature on tsunamis in recent years has been particularly relevant, since a number of research groups are devoting their efforts to study historical and recent tsunamis, as well as paleoevents affecting the European coasts. Hence, the tsunami database has been updated to include all recent scientific contributions, which implies modifications to both the event database as well as the references database. To better illustrate this point, let us suppose that a paper deals with $\mathrm{N}$ tsunamis: first, the paper is given a unique identification code $\mathrm{rxxx}$, then all $\mathrm{N}$ tsunami entries are accordingly changed by including the paper reference in the Description sub-box, and furthermore, the database of the references is incremented by the addition of the new entry.

One of the items displayed in the main screen of the catalogue indicates whether the tsunami event has been revised or not (see the sub-box in the left upper corner in Fig. 1): "yes" means that the authors of the catalogue performed a critical scrutiny of the data sources (coeval and post-coeval). In the GITEC 1.1 catalogue the revised events happen to be unequally distributed in space and in time. Most of the revised events belong to the regions of the Norwegian Sea, of the Atlantic Ocean, of central Mediterranean and of Black Sea. Here, revisions were generally carried out on historical and modern events, while in the other regions usually only the most recent events were carefully examined. All the GITEC 1.1 events having the revision item set to "not" were not reexamined by the GITEC working team, though 

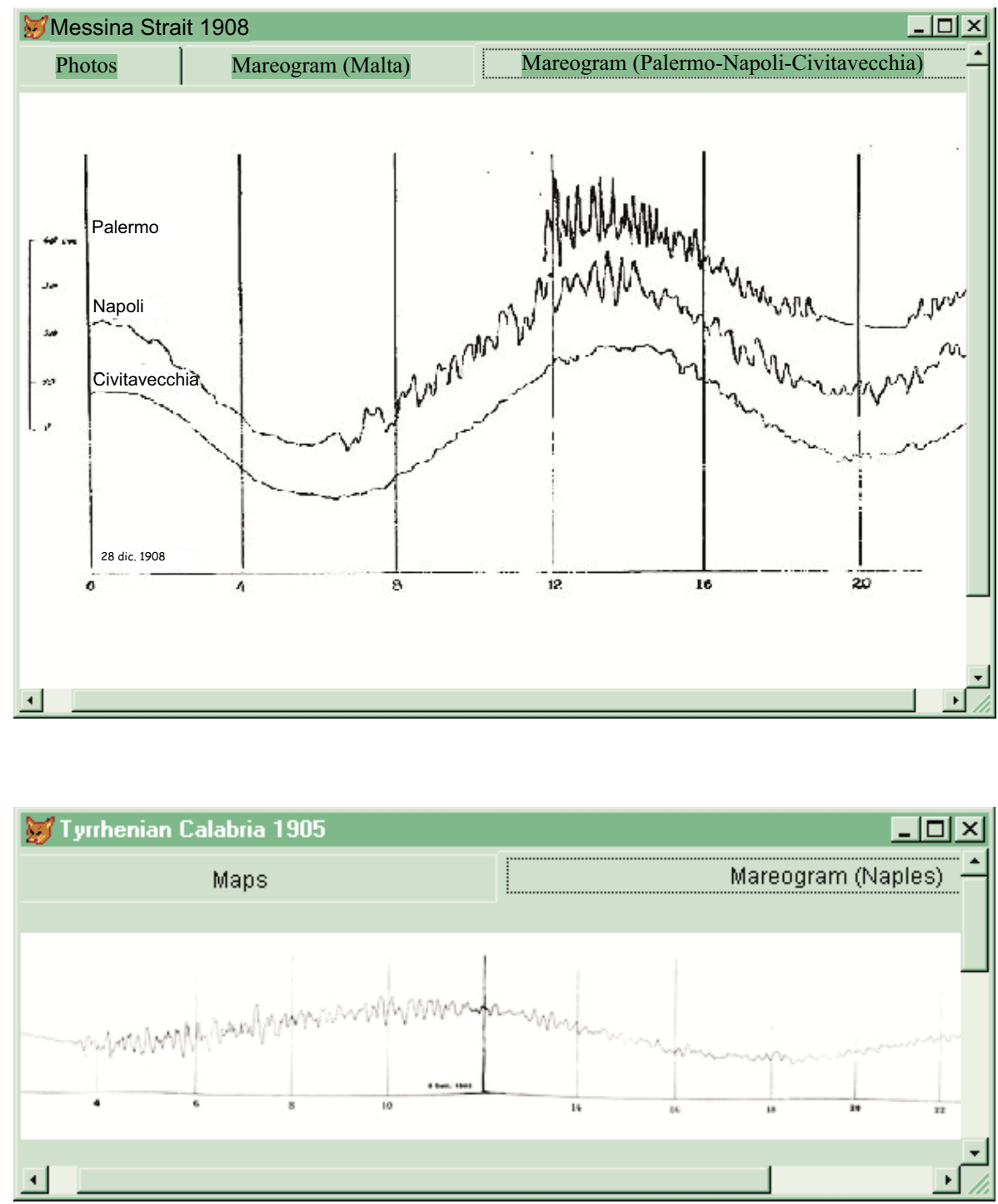

Fig. 4. Tide-gauge records of the Messina Strait 1908 tsunami from three different cities (Palermo, Napoli and Civitavecchia) which are located at increasing distance from the source. The diagram is displayed by selecting the rightmost item from the top menu.

Fig. 5. Mareogram recorded by the tide gauge of Naples for the Tyrrhenian Calabria 1905 tsunami. Like images of Figs. 3 and 4 this is an illustrative example of the content of the graphical data archive.

their inclusion in the catalogue always implies that some basic check on the quality and reliability of the data was carried out. There are, however, a number of cases mentioned in previous catalogues or in some other publications (i.e. in catalogues by Soloviev, 1990; Soloviev et al., 1997; Antonopoulos, 1980; Galanopoulos, 1960; Caputo et al., 1984) that the GITEC working group of experts considered to be supported by at lack of insufficient evidence to deserve insertion in the catalogue and that were left out accordingly. For example, the total number of events affecting the Italian coasts that can be found in the GITEC catalogue is less than $50 \%$ of the cases listed in the Caputo et al. compilations of Caputo et al. (1984, 1986). We focus our study on the reappraisal of those Italian cases excluded from the GITEC release that are attributed to years in the period 1800-1978: it is a total of 34 cases that were quoted in Caputo's catalogues, but that had no entry either in the Tinti and Maramai catalogue (1996) or in the GITEC. The bulk of the work consisted of undertaking an extensive and careful search for data in the most important
Italian libraries, where the available newspapers collections (about 50 listed in Appendix A were searched through, and in some public archives, both ecclesiastic and municipal. In addition, for the cases of the last century, the Italian news agencies databases were further consulted.

The result of our investigation is that all cases examined, except for two, do not possess the characteristics of a tsunami: they are either waves excited by meteorological perturbations or false events. On the other hand, the fact that two cases are judged to have the rank of possible tsunami events and hence, have been included in the European tsunami catalogue is a success. These occurred on 4 July 1809 in the Ligurian Sea and on 15 January 1940 on the northern Sicily coasts.

The 1809 event took place in the La Spezia Gulf, on the easternmost sector of the Ligurian Sea, with no certain cause, but the morphology of the sea bottom in this area justifies the hypothesis of the occurrence of a submarine landslide exciting the water waves. On the basis of the col- 
lected descriptions we attributed to this event reliability 2 (which means that there is no certainty that it was a tsunami, and is still a "questionable tsunami") and intensity 2 on the Ambraseys-Sieberg scale (Ambraseys, 1962), characterising "light" tsunamis with waves generally noticed on very flat shores. Hereafter the most significant part of the original description found in the "Gazette Nationale" (1809) is reported: "...the inhabitants of La Spezia and those living in the whole gulf observed an extraordinary tide on 4 July. ... At about 8 a.m. the sea, that till then was absolutely calm, suddenly rose about $1 \mathrm{~m}$ above its usual limit. This extraordinary tide lasted for about 15-20 min rising and falling. No apparent cause was observed. ... The tide was so strong and quick that the sea water flew up to the city of La Spezia through a small canal that crosses the city itself. Some merchants that were settled in the embankments ran away. ... Large parts of the low beach were left dry and some big fishes were dragged by the water and trapped in the dried beach ... The first flux of the sea water was followed by 4 or 5 others that gradually diminished their strength. ... We can suppose that the effects of this extraordinary tide was due to some seismic shock, or submarine or in land." We observe that the description (wave height, number, period, etc.) is rather appropriate for a tsunami, but we also point out our disagreement with the reporter of the newspaper on the possible cause of the event. The hypothesised tsunamigenic shock is improbable since an earthquake large enough to generate a tsunami cannot pass unfelt to the entire population, both onshore and offshore, while a submarine slide can certainly pass undetected.

The 15 January 1940 event is associated with a strong earthquake (VIII MCS), with epicenter located inland about $20 \mathrm{~km}$ far from the coast of Palermo, in northern Sicily. It caused one death and severe damage in some localities. According to the Sicilian newspaper "L'Ora" (1940), and an account of the "Ufficio Centrale di Meteorologia e Geodinamica" (1940), some people in Palermo noted a strong agitation of the sea water just a few seconds before the shock, and immediately after the shock some sudden water waves were observed in the gulf. The evaluation of sources led us to attach reliability 2 and intensity 2 to this event, as in the previous case. As mentioned before, we have eliminated 32 cases since we judged them to be either false events or phenomena which lack the typical characteristics of tsunamis. One of these is discussed here below, as an illustrative example. It belongs to a class comprising of several cases where sailmen felt their boats and vessels in the sea shaken by waves after an earthquake: since this is an expected effect of seismic P-waves hitting the boats, and not a sign of an occurring tsunami, we have decided to cancel all those entries which have no further evidence of a tsunami. On 15-16 November 1892, the Ponza Island (Latium) in the Tyrrhenian Sea was shaken by a series of earthquakes. Caputo and Faita (1984) include this event in their catalogue as a tsunami, quoting Baratta (1901), who reports that many seismic shocks were felt in the Ponza and in Ventotene Islands, causing no damage, and who writes: “... in the sea near Punta della Guardia, in the southern part of the island
(Ponza), some people on a boat felt a strong blow". This is the only piece of information used by Caputo and Faita to justify the tsunami occurrence. During our revision, starting from Baratta's clue, we searched for further information, and were able to find a lot of accounts regarding the seismic shocks, but no further data on some anomalous sea behaviour. The largest quake occurred at 02:12 GMT on 16 November with epicentral intensity 5.5 (MCS scale), corresponding to the macroseismic magnitude 3.8 , according to the ING earthquake catalogue (1991). Most of the examined sources state that the whole population of the island escaped to the beach during the seismic sequence, and therefore it is very plausible that an attacking tsunami, though very small, could not have passed unnoticed. The most reliable hypothesis to explain Baratta's description is therefore that fishermen felt the impact of the $\mathrm{P}$-waves propagation in the water against their boat and that no tsunami was generated by such small quakes.

At present we are carrying out investigations on some anomalous phenomena observed along the Italian coast, probably related to two shocks that occurred in the southern Mediterranean, respectively, on 28 August 1962 and on 22 June 1978. In 1962 a destructive earthquake that occurred in the Peloponnesus area (Greece) was strongly felt in many regions of southern Italy causing damage in Apulia and Calabria. According to the descriptions found in some newspapers, anomalous sea waves were observed by several people in the Gulf of Taranto. In particular, "Il Corriere del Giorno", that is published in Taranto, on 29 August 1962 reports that “... at Metaponto, Scanzano, Policoro and Nova Siri the effect of the earthquake was a tsunami. The sea water suddenly got rough, and violent waves struck the beach ...".

Regarding the 22 June 1978 case, what is reported is that after a violent shock located near Thessaloniki, some extraordinary waves affected the Italian Adriatic coasts from Abruzzo to Apulia, with sea withdrawals and floodings. Many newspapers provide detailed accounts of the event and here an exemplifying extract from the newspaper called "Il Messaggero" (1978) is quoted: “... the phenomenon of anomalous tides has been observed along the whole coast of Abruzzo, particularly in the Teramo, Pescara and Chieti areas, as far as Termoli, where it has been strongly expereinced. The Termoli harbour dried up; the sea first withdrew by tens of metres and then violently inundated the shore ... Also in Bari anomalous sea behaviour was observed with irregular tides, and some ships were aground ... A lot of fish were found on the beach ...".

Both cases are still under study, since further analysis is needed before the decision can be taken on their possible inclusion in the European tsunami catalogue.

\section{Conclusions}

In this paper the work undertaken to produce a new version of the European tsunami catalogue has been illustrated. The GITEC release 1.1 based on the FoxPro 2.5 DBMS package 
has been rebuilt and restyled by using the Visual FoxPro 6.0, suitable for the current PC operating systems. Though the basic structure of the catalogue has remained unaltered, new features have been implemented, the most relevant being the addition of a database of graphical data that can be accessed by the main catalogue screen through the button titled "Images": this collection of images contains tide gauge records, maps and photos for the most relevant tsunamis.

The new version has been enriched by inserting the most recent scientific publications dealing with European tsunamis in the database of the references as well as in the entries of the corresponding tsunamis. The bulk of the work has been devoted to consider cases that were not included in the GITEC catalogue due to insufficient lack of documentary support. Out of 34 cases that were investigated, only two have been judged to deserve inclusion in the European catalogue: they are small events (with attached reliability 2) that occurred in the Gulf of La Spezia and in the Gulf of Palermo in north and south Italy respectively. We remark that although the addition of these two cases to the existing database is a change too small to modify the general picture of the distribution of the tsunami sources around Europe, the La Spezia case is quite interesting since it could be a further confirmation of the potential hazard resulting from unstable submarine sediment masses in the Ligurian Sea, and provides justification to undertake a detailed investigation of the sea bottom morphology and stability in that region.

Our work of catalogue updating is planned to continue, with the next activities being first focused on Norwegian and Portuguese tsunamis in cooperation with the GITEC partners, while the following step will be the reanalysis of the catalogue events with reliability 0 and 1 , purposedly in the attempt of reducing the uncertainty that there is now on their occurrence.

Acknowledgements. This research was carried out on funds from the Gruppo Nazionale di Difesa dai Terremoti (GNDT) of the Istituto Nazionale di Geofisica e Vulcanologia (INGV) and from the Ministero dell'Università e della Ricerca Scientifica e Tecnologica (MURST)

\section{Appendix A}

Consulted newspapers collections, distinct by decades, spanning the period 1801-1978

\section{1-1810}

Gazette Nationale, Giornale Italiano, Monitore Napoletano, Giornale del Campidoglio

\section{1-1820}

Gazette Nationale, Giornale Italiano, Giornale Pol. del Dipto. di Roma, Gazzetta di Milano, Gazzetta Piemontese, Giornale delle Due Sicilie

\section{1-1830}

Gazette Nationale, Gazzetta di Milano, Gazzetta Piemontese, Giornale delle Due Sicilie, Gazzetta di Venezia, Gazzetta di Mantova

1831-1840
Gazette Nationale, Gazzetta di Milano, Gazzetta Piemontese, Giornale delle Due Sicilie, Gazzetta di Venezia, Gazzetta di Mantova

\section{1-1850}

Gazette Nationale, Gazzetta di Milano, Gazzetta Piemontese, Giornale delle Due Sicilie, Gazzetta di Venezia, Gazzetta di Mantova

\section{1-1860}

Gazette Nationale, Gazzetta Piemontese, Giornale delle Due Sicilie, Gazzetta di Venezia, Gazzetta di Mantova, Giornale di Roma

\section{1-1870}

Gazette Nationale, Gazzetta Piemontese, Gazzetta di Venezia, Giornale di Roma, La Nazione, L'Osservatore Romano, Roma

\section{1-1880}

Gazzetta di Venezia, Gazzetta Piemontese, La Nazione, L'Osservatore Romano, Roma, La Capitale, Il Piccolo Giornale di Napoli, La Libertà, La Gazzetta del Popolo, Fanfulla, La Voce del Popolo, Gazzetta Ufficiale di Roma, Il Corriere della Sera, Gazzetta d'Italia, L'Italie, Il Cittadino, L'Adriatico, Il Tempo

\section{1-1890}

Gazzetta Piemontese, Gazzetta di Venezia, La Nazione, L'Osservatore Romano, Roma, La Capitale, La Gazzetta del Popolo, Il Corriere della Sera, L'Italie, Il Mattino, Il Messaggero, La Tribuna, Gazzetta di Napoli, Il Secolo XIX, Le Figaro, L'Epoca, Il Corriere Mercantile, Il Commercio, Il Caffaro, Il Cittadino

\section{1-1900}

Gazzetta di Venezia, La Nazione, L'Osservatore Romano, Roma

\section{1-1900}

La Capitale, La Gazzetta del Popolo, Il Corriere della Sera, L'Italie, Il Mattino, Il Messaggero, La Tribuna, Il Corriere di Napoli, Il Giornale di Sicilia, Il Mezzogiorno, Il Secolo XIX, Il Caffaro

\section{1-1910}

Gazzetta di Venezia, La Nazione, L'Osservatore Romano, Roma, La Capitale, La Gazzetta del Popolo, Il Corriere della Sera, Il Mattino, Il Messaggero, La Tribuna, Il Corriere di Napoli, Il Giornale di Sicilia, Il Secolo XIX, L'Ora, L'Avvenire d'Italia, Avanti, Il Giornale d'Italia

\section{1-1920}

La Nazione, L'Osservatore Romano, La Gazzetta del Popolo, Il Corriere della Sera, Il Mattino, Il Messaggero, La Tribuna, Il Corriere di Napoli, Il Giornale di Sicilia, L'Avvenire d'Italia, Il Giornale d'Italia

\section{1-1940}

La Nazione, L'Osservatore Romano, La Gazzetta del Popolo, Il Corriere della Sera, Il Mattino, Il Messaggero, La Tribuna, Il Corriere di Napoli, Il Giornale di Sicilia, L'Avvenire d'Italia, Il Giornale d'Italia, La Gazzetta del Mezzogiorno

\section{0-1978}

La Nazione, L'Osservatore Romano, La Gazzetta del Popolo, Il Corriere della Sera, Il Mattino, Il Messaggero, La Tribuna, Il Corriere di Napoli, Il Giornale di Sicilia, 
L'Avvenire d'Italia, Il Giornale d'Italia, La Gazzetta del Mezzogiorno, Il Corriere Adriatico, Il Corriere del Giorno, Il Corriere di Sicilia, L'Ora, La Sicilia, Roma

\section{References}

Ambraseys, N. N.: Data for investigation on seismic sea waves in the Eastern Mediterranean, Bull. Seism. Soc. Am., 52, 895-913, 1962.

Antonopoulos, J.: Data from investigation of seismic sea-wave events in the Eastern Mediterranean from the birth of Christ to 1980 A. D., Annali di Geofisica, 33, 141-428, 1980.

Baratta, M.: Il Vesuvio e le sue eruzioni. Dall'Anno 79 d. C. al 1896, Roma, 1897.

Baratta, M.: I terremoti d'Italia, F.lli Bocca, Torino, 1901.

Bedosti, B. and Caputo, M.: Primo aggiornamento del catalogo dei maremoti delle coste italiane, Atti Accademia Nazionale dei Lincei, Rendiconti Classe Scienze Fisiche, Matematiche, Naturali, Roma, Serie VIII, 80, 570-584, 1986.

Caputo, M. and Faita, G.: Primo catalogo dei maremoti delle coste italiane, Atti Accademia Nazionale dei Lincei, Memorie Classe Scienze Fisiche, Matematiche, Naturali, Roma, serie VIII, 17, 213-356, 1984.

Galanopoulos, G. A.: Tsunamis observed on the coasts of Greece from antiquity to present time, Annali di Geofisica, 13, 369-386, 1960.

Gazette Nationale: 18 July, Paris, 1809.

GITEC (Genesis and Impact of Tsunamis on the European Coasts): financed by the European Union under the contract EV5V-CT920175 .

GITEC-TWO (Genesis and Impact of Tsunamis on the European Coasts- Tsunami Warning and Observations): financed by the European Union under the contract ENV4-CT96-0297.

Heck, N. H.: List of seismic sea-waves, Bull. Seism. Soc. Am., 4, 269-286, 1947.

Il Corriere del Giorno: 29 August, Taranto, 1962.
Il Messaggero: 22 June, Rome, 1978.

ING (Istituto Nazionale di Geofisica): Catalogo dei oti italiani dal 1450 a. C. al 1990, Internal File, Roma, 1991.

L'Ora: 16 January, Palermo, 1940.

Mallet, R.: Catalogue of Recorded Earthquakes 1606 B. C. -1850 A. D. Reports on the State of Science. Third Report on the Facts of Earthquake Phenomena, British Assoc., For the Advancement of Science, London, 1852-1854.

Mercalli, G.: Vulcani e Fenomeni Vulcanici in Italia, Milano, 1883.

Moreira, V. S.: Tsunamis Obervados en Portugal, Serviço Meteorológico Nacional, R. T. 993, Publicaçao Geo, 134, Lisboa, 12, 1968.

Papadopoulos, G. A. and Chalkis, B. J.: Tsunamis observed in Greece and surrounding areas from antiquity up to present time, Mar.Geol., 56, 309-317, 1984.

Papazachos, B. C., Koutitas, Ch., Hatzidimitriou, P. M., Karacostas, B. G., and Papaioannou, Ch. A.: Tsunami hazard in Greece and surrounding areas, Ann. Geophysicae, 4, 79-90, 1986.

Soloviev, S. L.: Tsunamigenic zones in the Mediterranean sea, Natural Hazards, 3, 183-202, 1990.

Soloviev, S. L., Go, Ch. N., Kim, Kh. S., Solovieva, O. N., and ShChetnikov, N. A., Tsunamis in the Mediterranean sea, 2000 BC-1991 AD, Russian Academy of Sciences, National Geophysical Committee, Institute of Oceanology, Scientific and Co-ordination Centre "Tsunami”, Moskow, 139, 1997.

Tinti, S. and Maramai, A.: Catalogue of tsunamis generated in Italy and in Côte d'Azur, France: a step towards a unified catalogue of tsunamis in Europe, Annali di Geofisica, vol. XXXIX, n. 6, 1253-1299, 1996.

Tinti, S., Baptista, M. A., Harbitz, C. B., and Maramai, A.: The unified European catalogue of tsunamis: a GITEC experience, Proc. International Conference on Tsunamis, Paris, 26-28 May 1998, 84-99, 1999.

Tinti S., Armigliato A., Bortolucci E., and Piatanesi A.: GITECTWO Final Scientific Report, January 1999.

Ufficio Centrale di Meteorologia e Geodinamica: Notizie sismiche pervenute all'UCMG per l'anno 1940, Roma, 1940. 